Original Research

\title{
Grieving as an Internal Factor of Nurse-Patient Interaction in a Dialysis Unit
}

\section{Ika Yuni Widyawati ${ }^{1}$, Nursalam Nursalam ${ }^{2}$, Kusnanto Kusnanto ${ }^{2}$, Rachmat Hargono ${ }^{3}$ and Pei-Lun Hsieh ${ }^{4}$}

${ }^{1}$ Doctoral Student, Faculty of Public Health, Universitas Airlangga, Surabaya, Indonesia

2 Faculty of Nursing, Universitas Airlangga, Surabaya, Indonesia

${ }^{3}$ Faculty of Public Health, Universitas Airlangga, Surabaya, Indonesia

${ }^{4}$ Chung Hwa University of Medical Technology, Taiwan

\begin{abstract}
Introduction: The quality of the nurse-patient interaction is one factor that affects the patient adherence, but a study that provides an overview of factors in the nurse-patient interaction in improving or maintaining dialysis patient adherence has not been found. The aim of this study was to provide an overview of the various factors involved in the interaction process between nurses and patients undergoing dialysis in relation to their adherence to fluid and dietary restrictions.
\end{abstract}

Methods: A qualitative research design with an interpretive phenomenology approach was used in this study. The researcher intends to interpret the findings of the research, in this case the activity of the dialysis patients, in order to get a picture of the various factors involved in the process of interaction between nurse and dialysis patient. The unit of analysis used in this study was the disclosure or exposure of the internal factors of the nurse-patient interaction process, especially in relation to fluid and dietary restrictions. There were 15 participants who were selected based on the inclusion criteria. In-depth interviews, with field notes, were used in this study as the data collection method.

Results: The analysis of the theme based on the goal of the research includes grieving, needs and values/morals, but in this article, the researchers only describe one theme - grieving.

Conclusion: This result provides an overview of the findings on nurse-patient interaction factors that can serve as baseline data for the development of nursing care, both in nursing assessments and interventions aimed at improving dietary adherence and the fluid restriction of dialysis patients.

\section{ARTICLE HISTORY}

Received: April 02, 2018

Accepted: June 25, 2018

\section{KEYWORDS}

dialysis patient; grieving; nurse-patient interactions

\section{CONTACT}

Ika Yuni Widyawati

\iy.widyawati@gmail.com $\equiv$ Faculty of Public Health, Universitas Airlangga, Surabaya, Indonesia

Cite this as: Widyawati, I., Nursalam, N., Kusnanto, K., Hargono, R., \& Hsieh, P. (2018). Grieving as an Internal Factor of Nurse-Patient Interaction in a Dialysis Unit. Jurnal Ners, 13(1), 64-71. doi:http://dx.doi.org/10.20473/in.v13i1.8005

\section{INTRODUCTION}

Dialysis is a treatment that can improve the quality of life of patients with End Stage Renal Disease (Chow \& Wong, 2010; Elliott, Gessert, Larson, \& Russ, 2014; Ginieri-Coccossis, Theofilou, Synodinou, Tomaras, \& Soldatos, 2008) despite the high cost of the therapy (Klarenbach, Tonelli, Chui, \& Manns, 2014). Dialysis has a wide range of consequences on various aspects of the patient's life, including physical, biological, psychological and social (Wijaya, 2005), and even death (Bradbury et al., 2007).
According to Perkumpulan Nefrologi Indonesia (2014), renal replacement therapy haemodialysis has become the most common treatment with a percentage of $82 \%$. According to the data, in Indonesia, the percentage of regular haemodialysis measures reached 95\% (703,139 patients) and in East Java, there have been more than 90,000 haemodialysis patients in this time (PERNEFRI, 2014).

Patients on dialysis have to face many challenges in their life, where they have to recognise the disease 
and the treatment that should be followed, as well as learning to cope with and adapt to all of the changes and new behaviours in their life (Royani, Rayyani, Behnampour, Arab, \& Goleij, 2013). Various stressors are experienced, making the dialysis patients unable to accept the changes and causing them to feel as if they have no control over their lives (Warrior, 2015).

The inability of the patient to execute self-control behaviours affects patients who are not always in favour of the treatment process (Warrior, 2015; Wijaya, 2005). Patients with chronic diseases are expected to be the manager of themselves who are focused on the concept of patient-centered care. The failure of management and the treatment of dialysis patients is more often due to the non-adherence of patients (Addo, 2015). Adherence issues patients undergoing haemodialysis mainly focus on adherence to fluid restrictions, diet, medication and long (hours) implementation dialysis (Al-Khattabi, 2014; Al-Orabi et al., 2015; Denhaerynck et al., 2007; Park et al., 2014; Vardanjani, Parvin, \& Shan, 2015). The non-adherence of patients on dialysis to program fluid restriction and diet has an impact on the occurrence of complications, promotes an increased length of stay, decreases productivity and can even cause death (Alikari, Matziou, Tsironi, Theofilou, \& Zyga, 2015; Payne, Eaton, Mee, \& Blount, 2013; Saran et al., 2003). The quality of patient health depends on the patient's adherence to the treatment regimens recommended (Martin, Williams, Haskard, \& Dimatteo, 2005). Few interventions to improve adherence diet and fluid restrictions in dialysis patients have been conducted. The success of interventions to improve adherence depends on a series of factors, such as the realistic assessment of the knowledge and understanding of the patient on the regimen of therapy given and clear communication between the health professionals and patients, as well as fostering a sense of trust in the therapeutic relationship (Martin et al., 2005).

Nurses play an important role in this regard. In addition to providing care, nurses also provide additional assistance to patients in the form of support that is interpersonal that aims to help patients effectively cope with stress, improve their welfare, as well as accelerating the recovery of their health (De los Ríos Castillo \& Sánchez-Sosa, 2002). The partnership and collaboration that exists between health professionals and patients can maximise compliance, foster patient satisfaction, and improve the health of the patients (Martin et al., 2005).

The nurse-patient relationship is a means of exchanging information and the ability to (Millard, Hallett, \& Luker, 2006), therefore the interpersonal nurse-patient interaction should be an important element in patient involvement in care. It helps to determine the success of the patients' treatment, including the patients' adherence to their treatment recommendations (Chatwin, 2008; Nordby, 2007; Stoddart et al., 2012).
A study of the literature gives an overview of the research results outside Indonesia with different communication cultures. The results from the literature studies (from various national journals) show that some studies confirm that nurse-patient interactions contribute to patient compliance. The research conducted by Ningsih, Rachmadi, \& Hammad (2012) revealed that the rate of patient compliance does not depend on demographic data, but on the quality of the interactions and other factors. Other studies showed that the factors affecting fluid intake include education, self-concept, the knowledge of the patients, the health professionals and family involvement (Kamaluddin, 2009). The research is quantitative in nature, while the interaction of the patient and nurse is a subjective process, so it is necessary to conduct the research using a qualitative design.

Qualitative research conducted prior to the topic interaction involving the factor of nurse-patient in patients with conditions of psychiatric disorder has been executed by Cleary, Edwards, \& Meehan (1999). Qualitative research on the excavation of the factors that influence the communication aspects of the nurse-patient's family was conducted by Loghmani, Borhani, \& Abbaszadeh (2014). Research that provides an overview of the nurse-patient interaction factors in relation to fluid-limiting and dietary adherence in dialysis units is relatively limited and needs to be done. The aim of this study is to provide an overview of the various factors in the interaction process of nurses and patients undergoing dialysis in compliance with fluid and dietary restrictions.

\section{MATERIALS AND METHODS}

This research uses a qualitative research design with the chosen approach being an interpretive phenomenology. This is because the researcher intends to interpret the findings of the research, in this case, the activity of the nurses and dialysis patients in order to get a picture of the various factors involved in the nurse interaction process with the dialysis patients. The unit of analysis used in this study is the disclosure or exposure of internal factors in the nurse-patient interaction process. In this study, the researcher used Interpretative Phenomenological Analysis (IPA) to clarify each participant's experience in detail and to find out any psychological meanings. The researcher choose IPA as the analysis method to examine the complex and emotionally laden topics. IPA is an useful methodology for examining that such topics (Smith \& Osborn, 2015). The process of analysis includes reading and re-reading, initial notes, developing emergent themes, searching for connections across the emergent themes, moving case by case and finally looking for any patterns across the cases. 


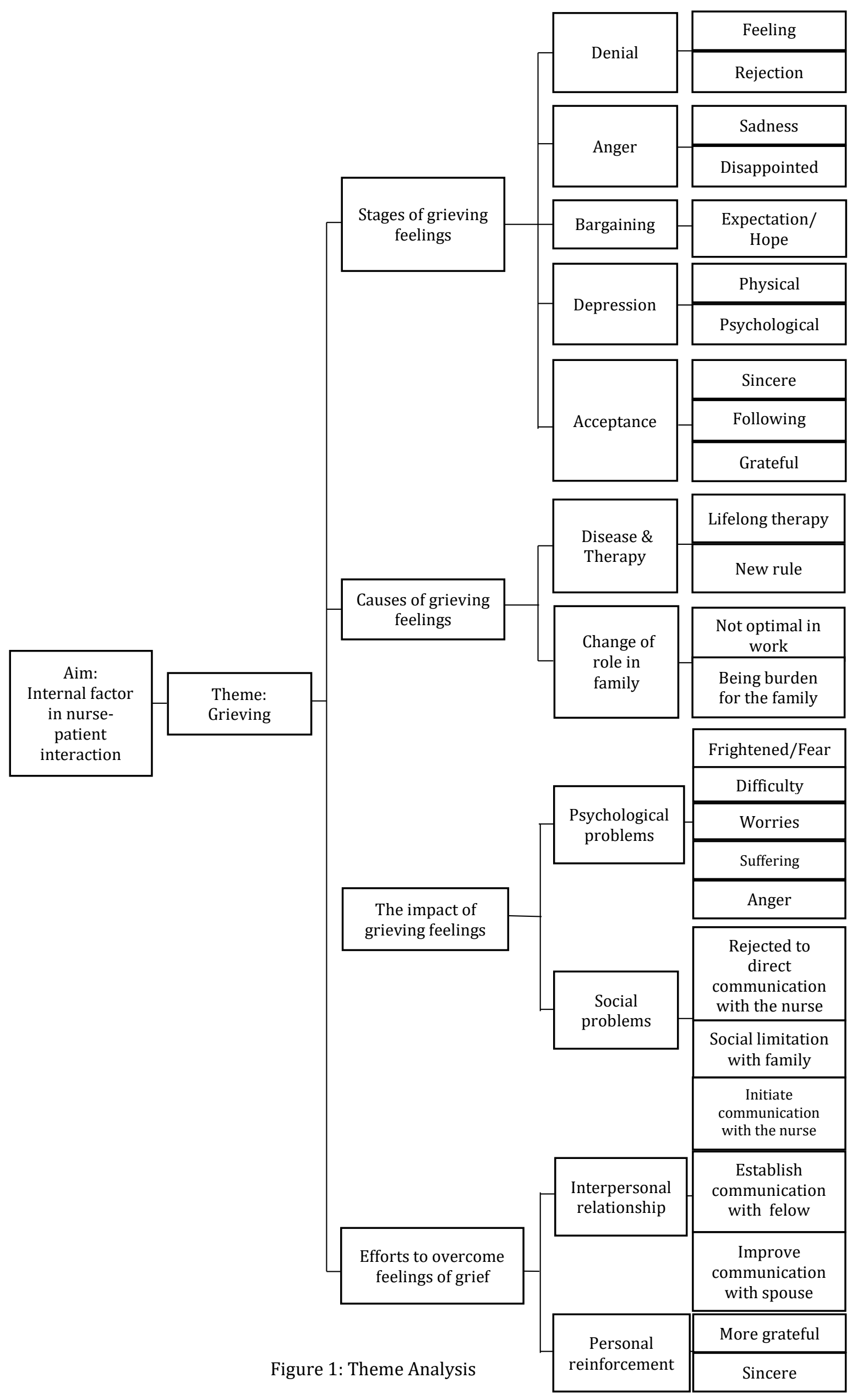


The inclusion criteria were that the patients had a minimum age of 18 years, were receiving similar dialysis therapy for at least 3 months, had a stable medical conditions (not currently in an acute condition requiring immediate medical treatment) and were not experiencing any psychological problems. As for the number of participants involved in the qualitative research, the method of selecting the participants in this study was not directed by quantity but based on the principle of conformity and adequacy until the number reached data saturation. The researcher reached data saturation when the information was repeated by the participants. The participants in this study included 15 patients who were selected based on the inclusion criteria and data that was saturated.

In-depth interviews complete with field notes were used in this study. The validity of the data was measured by validating the transcription of the interview results from the participants. Interresearcher and theory triangulation were used to maintain data stability and to maintain the objectivity of the data. The aim of triangulating the data by involving fellow researchers was to enrich the findings, while the theory triangulation conducted by researchers using the theory of nursepatient interactions from Imogene King was in order to have another perspective about what the nursepatient interaction is. The research study was ethically approved by Medical Research Ethics Commission Faculty of Nursing Universitas Airlangga No.: 326-KEPK.

\section{RESULTS}

\section{Characteristics of Participants}

There were 15 participants involve in this study. All of the participants live in Surabaya. The gender of the participants was 7 women and 8 men. The age of the participants varied with the age of the youngest participant being 21 years old and the oldest, 63 years of age. The education level of the participants ranged from elementary school to holding a graduate degree. The type of the work that the participants did consisted of private employees, retired village officials, retired soldiers and housewives.

\section{Theme Analysis}

The mourning feeling became one of the themes that emerged as an internal factor of the nursepatient interaction process. Feeling heartbroken was conveyed by several participants, and in this theme, there were several sub-themes, namely the stages of grieving, the causes of the grieving feelings, the impact of the grieving feelings and efforts undertaken to overcome the feelings of grief (Figure $1)$.

\section{DISCUSSION}

Grieving is a response of the neuropsychological experience of loss of an object or subject that has a meaning in the individual's life and is associated with the degree of suffering experienced (Bruce, 2007). The mourning feeling in this research consists of sub-themes that include the stages of grief, the cause of grief, the impact of grief and the overcoming of grief. This finding revealed a new theme in the influencing factors of the nurse-patient interactions in an effort to realise patient compliance with fluid and diet restrictions.

Other studies which focus on the factors that influence nurse-patient interactions take up the area of mental nursing as conducted by Cleary, Edwards, \& Meehan (1999) and Sharac et al. (2010). The results of this study were different from the other mentioned two studies. In the research conducted by Cleary, Edwards, \& Meehan (1999), patient factors lead to the increased severity of the disease, whereas in this study, it was found that the three themes in the internal factors of the patient involved was feeling sorrow, needs and norms / morals (which will be described separately). The differences that arose according to the researchers was due to several things. In this study, the researchers conducted in-depth interviews with the participants (dialysis patients) and their caregivers to gain an overview of the various things that affect the interaction of the nurse-patient within the setting of the room (a dialysis unit). In the research conducted by Cleary, Edwards, \& Meehan (1999), the participants selected were nurses with patients with psychiatric disorders in a psychiatric unit setting. The research conducted by Sharac et al. (2010) was a research study that aimed to obtain a picture of the activity of the nurse-patient interaction in the psychiatry room by reviewing some of the research results.

The grief experienced by the patient has an impact on the nurse-patient interaction initiation process, which is indicated by the results of this study. The nurse-patient interaction is a fundamental aspect in the process of providing and receiving nursing care (Chatwin, 2008; Nordby, 2007; Shattell, 2004; Williams \& Irurita, 2004). The expression of feelings by the patients refers to each stage of grieving, according to the theory of mourning conveyed by Kubler Ross (1969), quoted by Potter \& Perry (2006). This result is consistent with the theory expressed by Bruce (2002), in that the mourning process begins at the stage of diagnosis due to changes in their experienced status which changes the trajectory of sadness to some degree.

Some of the participants said that in the initial phase of diagnosis, the participants felt like they had not been able to accept their condition, which was shown by the expression of denial, anger and depression. This study has not delved deeper into how the stages of grieving over a certain time frame, so it is not known whether the stages of grieving is an iterative process or a process that is stagnant and stops at a certain point in time. The researcher focused on the nurse-patient interaction process in the beginning (by having participants recall the 
initial interaction process) to the continuous nursepatient interaction process at the time of the meeting (which refers to the patient's continuation of their compliance with diet and fluid restrictions).

The causes of grief identified in this study include illness, action and the role change in the family. The verdict of the disease, the therapy to be followed, the suggestions to be followed and the physical changes experienced are important experiences for the participants and cause physical and psychological discomfort. The initiation of patient interaction and the interaction itself becomes fundamental to the development of the nurse-patient relationship (Stoddart et al., 2012). The nurse-patient relationship can be realised by the active involvement between individuals who both feel comfortable and in good condition or who are healthy (Hagerty \& Patusky, 2003). Depression experienced by the participants and their perceptions of the impact of the disease experienced was an important response of the patients with endstage renal disease (Kimmel, 2000, 2001), which needs to be considered by the nurses when initiating interactions with the patients.

Another cause of grief that was identified in this research was the change of role in the family. Categories that are in this sub-theme are that they are no longer optimal at work and become a burden on the family. The role change in the family became a unique finding of this study. Another study that has discussed the role-related changes in families that affects the interaction process has not been found by the researchers. It is important to realise that the stress and frustration that is felt when experiencing kidney failure as well as therapy and the rules to be followed is a real condition and it is difficult for those who experience it. For patients, this is a great crisis and it transforms a large part of their life. The patients undergo confusion and tension facing the disease, and they remain concerned about the process of the therapy or the health problems that can suddenly arise as a complication or consequence of noncompliance, even when it comes to distractions in everyday life. Kidney failure requires lifestyle changes. Routines and activities that require physical strength are more difficult for the patients to do, so their family or friends may have to take on additional responsibilities. This role change is also a burden felt by the participants of this study.

The effects of the grieving feelings that can be identified in this study include both psychological and social problems. Categories included in the psychological problems are the emergence of fear, distress, worry, and feelings of pain and anger. In patients with end-stage renal disease, those undergoing routine dialysis were upset because the disease had happened to them. There was also the fear of the possibility that they could die (for those who were not ready to face death). The patients feel helpless because they cannot do anything about the disease. This gives rise to feelings of frustration and anger against the health workers. Anger can arise due to their dependence on others (National Kidney Foundation, 2017). The participants' 6 examples convey that the initial pain and needing dialysis makes the participants feel afraid to start communicating with the nurses, their partner or their children. The six participants explained that the condition gradually began to change after the nurse continuously approached and provided an explanation of the various things brought into question by the participant and their family. This will be explained further in the internal factors (nurse) and externally, in the interaction process.

Feelings of grieving are actually a normal process, although sometimes the process can take a long time and be complicated (Bruce, 2007). In patients with chronic diseases, the feelings that arise because of the disease experienced (more predominantly, the existence of a negative perception) often causes conflict in their relationships with others (Wortman \& Dunkel-Schetter, 1979). This conflict resulted in behavioural responses that inadvertently harmed the patient, including avoiding open discussion of the disease (Wortman \& Dunkel-Schetter, 1979). Researchers classify this condition as a social problem, which is a behavioural response that impacts on any interpersonal relationship problems. Efforts to avoid open discussion of the disease were indicated by 9 participants who refused direct communication with the nurses, while 13 participants limited socialising with their family. Another study by Rogers (2002) also showed the same characteristics in the nurse-patient interaction, in that the patient will cooperate with the nurse when the interaction is considered beneficial and is done actively. The patient became uncooperative when the interaction was not considered beneficial for them. Thus, it should be an important concern of the nurses when interacting with patients.

Efforts to overcome the feelings of grieving shown by the participants in this study include strengthening their interpersonal relationships and personal factors. The results of this study have shown that every participant who experiences feelings of mourning (because of pain conditions, therapy and lifestyle changes) have different reactions. This is in line with the results of the research conducted by Silva et al. (2016), where the reaction to the disease and the strategies used by each individual can lead to treatment that focuses on emotion or focuses on the medical issue itself. Handling the focus on emotions in the study by Silva et al. (2016) is characterised by supporting their religion / faith, the search for family support, denial and avoidance. In this study, the treatment or remedy is indicated by communicating with fellow patients and improving communication with their partner. Both are forms of interpersonal relationship that lead to finding good support from family and their fellow patients (peers).

In the study by Silva et al. (2016), it reveals the countermeasures found by focusing on the problems that are represented by resilience as a way to give 
new meaning to their experience, in order for them to realise the importance of adherence to therapy and their treatment in an effort to minimise the problem. In this study, the treatment or remedy is indicated by strengthening personal efforts where the individuals show reception prior to the problem they are facing and then look for a solution to the problem. The handling is an important factor that must be considered for health promotion and to improve the quality of life of the patients. Knowledge of countermeasures would allow the health care team to provide adequate support to prevent pessimism and despair in terms of living with the disease (da Silva et al., 2016).

\section{CONCLUSION}

Based on the research results, we were able to conclude that there are two factors that affect the nurse-patient interaction; internal factors and external factors. Feelings of mourning were one of the themes that emerged as an internal factors of the nurse-patient interaction process in the dialysis unit. Feelings of mourning in this study consisted of subthemes, namely the stages of grieving, the cause of the feeling of mourning, grieving and feeling the impact of their efforts to overcome the feelings of grief. The results of this study are expected to be a material consideration in proper nursing care and the development of appropriate nursing interventions for each of the issues that arise in each phase experienced by the patient. This is as well as the materials for the professional development of the nurses and nursing quality improvement. The limitations of this study are based on the limitations of the supporting literature and other research results when discussing this topic in a specific area such as that of dialysis patients.

\section{REFERENCES}

Addo, E. (2015). Chronic Care Model Staff Education and Adherence with End-Stage Renal Disease Patients. Walden University. Retrieved from http://search.proquest.com/docview/17506457 91?accountid=13042\%5Cnhttp://oxfordsfx.host ed.exlibrisgroup.com/oxford?url_ver=Z39.8820 04\&rft_val_fmt=info:ofi/fmt:kev:mtx:dissertatio n\&genre=dissertations $+\&+$ theses \&sid=ProQ:Pro Quest+Dissertations+\&+Theses+Glo/(Accessed: March 27, 2018).

Al-Khattabi, G. H. (2014). Prevalence of Treatment Adherence among Attendance at Hemodialysis in Makah. International Journal of Medical Science and Public Health, 3(5), 592-598. https://doi.org/10.5455/ijmsph.2014.1703201 41/ (Accessed:March 27, 2018).

Al-Orabi, M. Q., Alshalawi, N. N., Alotaibi, M. M., Abdallah, M. A. A., Yousif, \& Elbur, A. I. (2015). Prevalence and Predictors of Non-Adherence to Medication among Patients on Hemodialysis in a Tertiary Care Hospital, Taif, Kingdom of Saudi
Arabia. European Journal of Pharmaceutical and Medical Research, 2(6), 18-23.

Alikari, V., Matziou, V., Tsironi, M., Theofilou, P., \& Zyga, S. (2015). The Effect of Nursing Counseling on Improving Knowledge, Adherence to Treatment and Quality of Life of Patients Undergoing Hemodialysis. International Journal of Caring Sciences, 8(2), 514-518.

Bradbury, B. D., Fissell, R. B., Albert, J. M., Anthony, M. S., Critchlow, C. W., Pisoni, R. L., ... Gillespie, B. W. (2007). Predictors of Early Mortality among Incident US Hemodialysis Patients in The Dialysis Outcomes and Practice Patterns Study (DOPPS). Clinical Journal of the American Society of Nephrology, 2(1), 89-99. https://doi.org/10.2215/CJN.01170905

Bruce, C. A. (2002). The Grief Process for Patient, Family, and Physician. Journal of the American Osteopathic Association, 102(9 Suppl 3), S28-S32.

Bruce, C. A. (2007). Helping Patients, Families, Caregivers, and Physicians in the Grieving Process. Journal of American Osteopathic Association, 107(7), 33-40. https://doi.org/10.1016/j.pec.2003.12.009

Chatwin, J. (2008). Hidden Dimensions: The Analysis of Interaction in Nurse - Patient Encounters. Quality in Primary Care, 16, 109-115.

Chow, S. K. Y., \& Wong, F. K. Y. (2010). Health-related Quality of Life in Patients Undergoing Peritoneal Dialysis: Effects of A Nurse-led Case Management Programme. Journal of Advanced Nursing, 66(8), 1780-1792. https://doi.org/10.1111/j.13652648.2010.0532 4.X

Cleary, M., Edwards, C., \& Meehan, T. (1999). Factors Influencing Nurse-Patient Interaction in The Acute Psychiatric Setting: An Exploratory Investigation. The Australian and New Zealand Journal of Mental Health Nursing, 8(3), 109-116. https://doi.org/10.1046/j.13652850.1999.0024 8.x

da Silva, R. A. R., de Souza, V. L., de Oliveira, G. J. N., da Silva, B. C. O., Rocha, C. C. T., \& Holanda, J. R. R. (2016). Coping Strategies used by Chronic Renal Failure Patients on Hemodialysis. Escola Anna Nery, 20(1), 147-154. https://doi.org/10.5935/14148145.20160020

De los Ríos Castillo, J. L., \& Sánchez-Sosa, J. J. (2002). Well-Being and Medical Recovery in The Critical Care Unit: The Role of The Nurse-Patient Interaction. Salud Mental, 25(2), 21-31.

Denhaerynck, K., Manhaeve, D., Dobbels, F., Garzoni, D., Nolte, C., \& De Geest, S. (2007). Prevalence and Consequences of Nonadherence to Hemodialysis Regimens. American Journal of Critical Care, 16(3), 222-236. Retrieved from http://www.scopus.com/inward/record.url?eid $=2$ s2.034250818890\&partnerID=tZOtx3y1

Elliott, B. A., Gessert, C. E., Larson, P. M., \& Russ, T. E. (2014). Shifting Responses in Quality of Life: People Living with Dialysis. Quality of LIfe 
Research,

23,

1497-1504. https://doi.org/10.1007/s11136-013-0600-9

Ginieri-Coccossis, M., Theofilou, P., Synodinou, C., Tomaras, V., \& Soldatos, C. (2008). Quality of Life, Mental Health and Health Beliefs in Haemodialysis and Peritoneal Dialysis Patients: Investigating Differences in Early and Later Years of Current Treatment. BMC Nephrology, 9(1), 14. https://doi.org/10.1186/1471-2369-9-14

Hagerty, B. M., \& Patusky, K. L. (2003). Reconceptualizing The Nurse-Patient Relationship. Journal of Nursing Scholarship, 35(2), 145-150.

Kamaluddin, R. (2009). Analisis Faktor yang Mempengaruhi Kepatuhan Asupan Cairan pada Pasien Gagal Ginjal Kronik dengan Hemodialisis. Jurnal Keperawatan Soedirman, 4, 20-25.

Kimmel, P. L. (2000). Psychosocial Factors in Adult End-Stage Renal Disease Patients Treated with Hemodialysis: Correlates and Outcomes. American Journal of Kidney Diseases, 35(4), 132140.

https://doi.org/10.1016/S02726386(00)70240$\mathrm{X}$

Kimmel, P. L. (2001). Psychosocial Factors in Dialysis Patients. Kidney International, 59(4), 1599-1613. https://doi.org/10.1046/j.1523-

1755.2001.0590041599.x

King, I. M. (2007). King's Conceptual System, Theory of Goal Attainment, and Transaction Process in the 21st Century. Nursing Science Quarterly, 20(2), 109111.https://doi.org/10.1177/08943184072998 46

Klarenbach, S. W., Tonelli, M., Chui, B., \& Manns, B. J. (2014). Economic Evaluation of Dialysis Therapies. Nature Reviews Nephrology, 10(11), 644-652.

https://doi.org/10.1038/nrneph.2014.145

Loghmani, L., Borhani, F., \& Abbaszadeh, A. (2014). Factors Affecting the Nurse- Patients ' Family Communication in Intensive Care Unit of Kerman: a Qualitative Study. Journal of Caring Sciences, $3(1)$, 67-82. https://doi.org/10.5681/jcs.2014.008

Martin, L. R., Williams, S. L., Haskard, K. B., \& Dimatteo, M. R. (2005). The Challenge of Patient Adherence. Therapeutics and Clinical RRsk Management, 1(3), 189-199. Retrieved fromhttp://www.ncbi.nlm.nih.gov/pubmed/183 60559/(Accessed:March 27, 2018).

Millard, L., Hallett, C., \& Luker, K. (2006). NursePatient Interaction and Decision-Making in Care: Patient Involvement in Community Nursing. Journal of Advanced Nursing, 55(2), 142-150. https://doi.org/10.1111/j.13652648.2006.03904.x

National Kidney Foundation. (2017). Coping Effectively: A Guide for Patients and their Families. Retrieved November 1, 2017, from https://www.kidney.org/atoz/copingeffectively-guide-patients-and-their-families
Ningsih, E. S. P., Rachmadi, A., \& Hammad. (2012). Tingkat Kepatuhan Pasien Gagal Ginjal Kronik dalam Pembatasan Cairan pada Terapi Hemodialisa. Media Jurnal Ners, 7(1).

Nordby, H. (2007). Meaning and Normativity in Nurse-Patient Interaction. Nursing Philosophy, 8(1), 16-27.

https://doi.org/10.1111/j.1466769X.2007.0029 3. $\mathrm{x}$

Park, H., Rascati, K. L., Lawson, K. A., Barner, J. C., Richards, K. M., \& Malone, D. C. (2014). Adherence and Persistence to Prescribed Medication Therapy among Medicare Part D beneficiaries on dialysis: comparisons of benefit type and benefit phase. Journal of Managed Care \& Specialty Pharmacy, 20(8), 862-876.

Payne, M. E., Eaton, C. K., Mee, L. L., \& Blount, R. L. (2013). Promoting Medication Adherence and Regimen Responsibility in Two Adolescents on Hemodialysis for End-Stage Renal Disease: A Case Study. Clinical Case Studies, 12(2), 95-110. https://doi.org/10.1177/1534650112467079

Perkumpulan Nefrologi Indonesia [PERNEFRI]. (2014). 7th Report Of Indonesian Renal Registry 2014. Retrieved from http://www.indonesianrenalregistry.org/\#cmt3 / (Accessed:March 27, 2018).

Potter, P. A., \& Perry, A. G. (2006). Buku Ajar Fundamental Keperawatan. Konsep, Proses, dan Praktik. (D. Yulianti \& M. Ester, Eds.) (4th ed.). Jakarta: Penerbit EGC.

Rogers, S. R. (2002). Nurse-Patient Interactions: What Do Patients Have to Say? The University of Texas.

Royani, Z., Rayyani, M., Behnampour, N., Arab, M., \& Goleij, J. (2013). The Effect of Empowerment Program on Empowerment Level and Self-Care Self-Efficacy of Patients on Hemodialysis Treatment. Iranian Journal of Nursing and Midwifery Research, 18(1), 84-87.Retrieved from http://www.pubmedcentral.nih.gov/articlerend er.fcgi?artid=3748561\&tool=pmcentrez\&render type=abstract/ (Accessed:March 27, 2018).

Saran, R., Bragg-Gresham, J. L., Rayner, H. C., Goodkin, D. A., Keen, M. L., Van Dijk, P. C., ... Port, F. K. (2003). Nonadherence in Hemodialysis: Associations with Mortality, Hospitalization and Practice in The DOPPS. Kidney International, 64(1), 254-262. https://doi.org/doi:10.1046/j.15231755.2003.00064.x

Sharac, J., McCrone, P., Sabes-Figuera, R., Csipke, E., Wood, A., \& Wykes, T. (2010). Nurse and Patient Activities and Interaction on Psychiatric Inpatients Wards: A Literature Review. International Journal of Nursing Studies, 47(7), 909-917. https://doi.org/10.1016/j.ijnurstu.2010.03.012

Shattell, M. (2004). Nurse-Patient Interaction: A Review of The Literature. Journal of Clinical Nursing, 13(6), 714-722. https://doi.org/10.1111/j.13652702.2004.0096 5.x 
Smeltzer, S., \& Bare, B. (2008). Brunner and Suddarth's Textbook of Medical-Surgical Nursing (10th ed.). Philadelphia: Lippincott Williams \& Wilkins.

Smith, J. A., \& Osborn, M. (2015). Interpretative Phenomenological Analysis as A Useful Methodology for Research on The Lived Experience of Pain. British Journal of Pain, 9(1),41-42. https://doi.org/10.1177/2049463714541642

Stoddart, K. M., Shattel, M., Chatwin, J., Williams, A., Irurita, V., Seiger, M., ... Svensson, R. (2012). Social Meanings and Understandings in Patient-Nurse Interaction in The Community Practice Setting: A Grounded Theory Study. BMC Nursing, 11(1), 14. https://doi.org/10.1186/1472-6955-11-14

Vardanjani, L. R., Parvin, N., \& Shan, G. M. (2015). The Effects of an Individual, Multistep Intervention on Adherence to Treatment in Hemodialysis Patients. Disability and Rehabilitation, 38(8), 1-5. https://doi.org/10.3109/09638288.2015.10616 01
Warrior, A. M. (2015). The Emotional Experience of American Indians receiving Hemodialysis and How It relates to Treatment Adherence. University of Nebraska.

Wijaya, A. (2005). Kualitas Hidup Pasien Penyakit Ginjal Kronik yang menjalani Hemodialisis dan mengalami Depresi. Universitas Indonesia.

Williams, A. M., \& Irurita, V. F. (2004). Therapeutic and Non-Therapeutic Interpersonal Interactions: The Patient's Perspective. Journal of Clinical Nursing, 13(7), 806-815. https://doi.org/10.1111/j.13652702.2004.01020.x

Wortman, C. B., \& Dunkel-Schetter, C. (1979). Interpersonal Relationships and Cancer: A Theoretical Analysis. Journal of Social Issues, 35(1), 35.

Zhang, Z. X., Luk, W., Arthur, D., \& Wong, T. (2001). Nursing Competencies: Personal Characteristics Contributing to Effective Nursing Performance. Journal of Advanced Nursing, 33(4), 467-474. https://doi.org/10.1046/j.13652648.2001.0168 8.x 